workshop for doctors working in a psychiatric hospital. BJPsych Bull 2008; 42; 211-6.

2 Denman C. Cognitive-analytic therapy. Adv Psychiatr Treat 2001; 7: 243-52.

3 Ryle A, Kerr IB. Introducing Cognitive Analytic Therapy: Principles and Practice. Wiley-Blackwell, 2002.

4 Chapman AL, Gratz KL, Brown MZ. Solving the puzzle of deliberate selfharm: the experiential avoidance model. Behav Res Ther 2006; 44: 371-94.

5 National Institute for Health and Care Excellence. Self-Harm in Over 8s: Long-Term Management. Clinical Guidance CG133. NICE, 2011. (https:// www.nice.org.uk/guidance/cg133)

6 Lloyd-Richardson E, Perrine N, Dierker L, Kelley M. Characteristics and functions of non-suicidal self-injury in a community sample of adolescents. Psychol Med 2007; 37: 1183-92.

doi:10.1192/bjb.2019.9

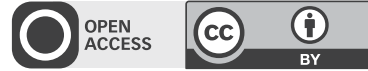

(C) The Authors 2019. This is an Open Access article, distributed under the terms of the Creative Commons Attribution licence (http://creativecommons.org/ licenses/by/4.0/), which permits unrestricted re-use, distribution, and reproduction in any medium, provided the original work is properly cited.

\section{Psychological aspects of wound management following self-harm on psychiatric wards}

I note with interest the initiative by Buick et al to evaluate a peer-led workshop on suturing skills for doctors working in psychiatric hospitals. ${ }^{1}$

The authors describe improved confidence of doctors with regards to suturing, associated with a reduction in transfers to accident and emergency (A\&E) departments and a significant potential cost saving (calculated at $£ 183.76$ for each transfer that is avoided). It would be interesting to learn whether the intervention was associated with any change in the frequency of self-harm on the psychiatric wards.

Albert et al make important comments on the benefits for doctors in continuing to apply their basic medical skills in this context, and point to a cognitive-analytic model to describe role reciprocity in the case of self-harming patients having interventions for their wounds. It would be interesting to investigate further how in-house physical treatment may differ from $A \& E$ treatment concerning rescuer-to-rescued roles and reinforcement.

I would like to suggest that the decision to provide physical treatments (including suturing) - or the decision not to do so will have an effect on the overall treating relationship and treatment frame.

What does it mean for a patient who expresses distress or hostility through cutting, when the doctor tasked with treating their psychological difficulties also becomes involved in the physically intimate act of suturing their body? How are the doctor's own emotional responses towards the patient's selfharm and the subsequent restorative procedure registered and managed when the doctor either performs the procedure directly, or sends the patient to A\&E?

Perhaps these complex emotional factors could also be worked out in peer groups - in particular through Balint or other psychological case-based discussion groups.

Alla Rubitel, Consultant Psychiatrist in Psychotherapy, Central and North West London NHS Foundation Trust; email: alla.rubitel@nhs.net

1 Buick TA, Hamilton D, Weatherdon G, O'Shea Cl, McAlpine G. Evaluating the effects of a peer-led suturing and wound management workshop for doctors working in a psychiatric hospital. BJPsych Bulletin 2008; 42, 211-6.

doi:10.1192/bjb.2019.10

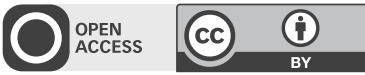

(c) The Authors 2019. This is an Open Access article, distributed under the terms of the Creative Commons Attribution licence (http://creativecommons.org/ licenses/by/4.0/), which permits unrestricted re-use, distribution, and reproduction in any medium, provided the original work is properly cited. 